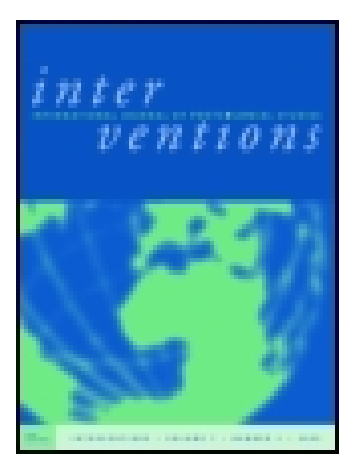

Interventions

International Journal of Postcolonial Studies

ISSN: 1369-801X (Print) 1469-929X (Online) Journal homepage: http://www.tandfonline.com/loi/riij20

\title{
Caribbean Artistic Genealogies of Withdrawal. Rethinking Caribbean Visuality Beyond Objecthood
}

\section{Carlos Garrido Castellano}

To cite this article: Carlos Garrido Castellano (2017): Caribbean Artistic Genealogies of Withdrawal. Rethinking Caribbean Visuality Beyond Objecthood, Interventions, DOI: 10.1080/1369801X.2017.1348243

To link to this article: http://dx.doi.org/10.1080/1369801X.2017.1348243

曲 Published online: 20 Jul 2017.

Submit your article to this journal $₫$

Q View related articles $\longleftarrow$

View Crossmark data ¿ 


\title{
CARIBBEAN ARTISTIC GENEALOGIES OF WITHDRAWAL. RETHINKING CARIBBEAN VISUALITY BEYOND OBJECTHOOD
}

\section{Carlos Garrido Castellano}

Universidade de Lisboa, Portugal

\begin{abstract}
.............. This essay examines how Caribbean artists have employed withdrawal in art institutions critical, insurgent ways. I confront several Caribbean projects developed in different chronologies and locations that have attempted to use withdrawal artistic agency in order to challenge uneven institutional dynamics. The examples I discuss biennials here - Cuban art dedicates itself to baseball (Havana, José A. Echevarría Stadium (Vedado), 1989), Silvano Lora's Marginal Biennial (Santo Caribbean studies Domingo, multiple locations, 1992), Joëlle Ferly's L'Art de faire la grève spectatorship (Martinique, Fondation Clément, 2009) and L'Artocarpe (Guadeloupe, ongoing) - problematize the role of artistic agency, the reach of the withdrawal exhibition form and the influence of foreign expectations. Traditionally, Caribbean art has been subjected to a process of commodification and exoticization. Through the examination of those four practices, I will assert that an alternative genealogy of active, productive interventions concerned with staging emancipative spatial dynamics beyond representational constraints and objecthood can be found.
\end{abstract}




\section{Introduction}

1 There are important theoretical antecedents for this task, with BuckMorss (2009) and Fischer (2004) as two of the best-known examples.
Dealing with the reception of C. L. R. James by Italian antiwork Marxism, Taylor (2014) has pointed out how the international success of books like Michael Hardt and Toni Negri's Empire implied eliciting James's influence and erasing the movements of flight carried out by slaves in the Caribbean. For him, this oblivion forms part of "a broader marginalization of Caribbean histories of slavery and emancipation in genealogies of antiwork Marxism" (Taylor 2014, 2). Discussing Negri's reading of antiwork and the Grundrisse, he argues "this hermeneutic of the tendency ... evacuates the past of any effective futurity while it simultaneously establishes a temporality of deferral for those spaces not yet incorporated into the ontological singularity of the future's present" (Taylor 2014, 4). Against this backdrop, Taylor sees in James a productive standpoint to think the role of antiwork theory as "the product of dislocated, transnational encounters" (5), and consequently away from hegemonic westernization and the boundaries of the nationstate. Through his study of slavery, Taylor argues, James found a space suitable to work in the construction of "postwork alternatives" (8), which was at the same time grounded and universally reverberating.

Although slavery and work have been approached by Caribbean artists and art critics on many occasions, the potential of antiwork in the configuration of emancipatory creative actions has somehow received less attention. Caribbean art has frequently been examined from the standpoint of productivity, objecthood and display. Under this logic, the usage of critical value within discursive and representational practices has centred the historiography about the art of the region, which normally privileges individual artists whose works are made to circulate widely internationally. Artistic objects emerge, then, as the vehicle and caretaker of emancipatory criticism, which is transferred to viewers through their contemplative observation. In this sense, the creative process is detached from its results; the labour invested in its creation from the final object. To a great extent, this process turns Caribbean art history into a history of exhibitions and individual artworks.

Theoretical conceptualizations such as Taylor's are crucial in asserting the centrality of the Caribbean region in the configuration of modernist thinking, while at the same time grounding and "provincializing" some of its elements. ${ }^{1}$ Borrowing this interest in eliciting the centrality of antiwork in Caribbean radical practice, and its transnational resonance, this essay's main concern is with the existence of alternative genealogies of Caribbean artistic practice based on an alternative articulation of artistic labour, criticality and reception. My interest here lies in exploring how Caribbean creative and curatorial practices have approached artistic labour, withdrawing and location in insurgent, critical ways. Those elements, I suggest, delimit and haunt the horizons of contemporary Caribbean creative practices. 
By analysing several initiatives that were attentive to the practical, infrastructural conditions determining artistic practice in specific Caribbean contexts, in this essay I seek to explore how both strategies can constitute alternative genealogies of Caribbean visual creativity, which are partially unexplored in (local and external) critical thinking on the matter. In this sense, I intend to see how they can illuminate the histories of Caribbean artistic practice in different ways. How can we appropriate productively, from a Caribbean perspective, the tradition of artistic withdrawal that constitutes a foundation of modernist aesthetics? Furthermore, what would the answers elaborated from the Caribbean region contribute to the current international debates on artistic labour and institutional withdrawal?

Assuming that those questions are worth exploring, my itinerary is as follows. First, I will consider how the concept of withdrawal became unhinged from its radical potential through its adoption by a tradition of avant-gardist aesthetics that sees it as a mode of detachment and deferral from "real" engagement and emancipation. Then, I will examine the major elements that centre the art criticism produced in and around the Caribbean, paying special attention to the role played by the production, display and circulation of artistic objects within and beyond the region. Finally, I will discuss several examples that constitute an alternative genealogy of Caribbean curatorial practices, justifying why an interpretation of Caribbean art from the perspective of labour and withdrawal is particularly poignant. My examples belong to different geographical contexts and historical moments; they represent, however, a constant trend in Caribbean artistic practice whose ramifications have been seldom explored. In this instance, I will limit my analysis to four examples committed to producing an active rethinking of withdrawal, although many others could have been chosen. I will then analyse how Caribbean curators and artists have decentred the space of curating, thereby mitigating the weight of biennials and mega-exhibitions while also instituting alternative, empowering curatorial strategies; how they have reflected on withdrawing and labour in productive, collaborative ways; and finally, how they have engaged with location and space.

\section{Withdrawal and avant-garde aesthetics}

The weight of productivity, discursivity and objecthood in Caribbean artistic practice has a long genealogy, which I will partially outline in the following sections. This genealogy, however, is also imbricated in the main tradition of western avant-garde art. Focusing on elaborating a critical framework to analyse dialogical practices, Grant Kester recognizes the use of withdrawal as a recurrent tendency among the successive waves of avant-gardist 
aesthetics. Kester $(2004,39)$ approaches the work of Clive Bell, Roger Fry and Clement Greenberg in order to assert that art's autonomy was to a great extent built on withdrawal from the disenchantment with "real" political change and on postponement of aesthetic transformation until the appearance of an "ideal viewer-yet-to-be". For Kester, the detachment from reality of avant-gardist artists is part of an elitist movement that undervalued positive and non-material interaction, stripping "non-productive", dialogical practices from the condition of aesthetic purity. More recently, he has developed this idea further, outlining that avant-gardist aesthetic tradition is based on negativity, on "laying bare" the construct represented by the ideological structure of the art system, which would remain hidden until the arrival of the "enlightened" artist:

The act of 'laying bare the device' implies an audience for whom the device was already concealed: a viewer who would be made suddenly aware of the existence of some structuring ideological mechanism that regulated what was previously experienced as his or her autonomous thought and action in the world. $(2013,14)$

The consequences of this process not only reinforce the agency of the artist at the expense of the audience, it also makes the relation between both dependent on an act of uncovering a concealed truth, limiting any other possible engagement. In that sense, Kester argues, more "constructive" ways of conceiving that relationship are discarded for supposedly being too much reliant on consensus or agreement. As a result of this, an aesthetic of failure is installed, one in which withdrawal is understood as a necessary detachment from reality: "A significant feature of the modernist tradition is an ongoing meditation on the ruins of discourse - artworks that are about the artist's inability to achieve the emancipatory communion that is anticipated by the aesthetic" $(2004,31)$. The most suitable aesthetic model for this scheme is disruption. Since viewers are used to being deceived, only through a negative and unfulfilled confrontation with reality can the spectator obtain an aesthetically enriching outcome. Any "social" or "political” elements ought to capitulate to this negativity, being incorporated as discursive elements and therefore denying any possibility of "real" collective change $(2011,42)$. The work of artists such as Santiago Sierra, who usually subjects the audience and outsourced actors to experience traumatic situations in "controlled environments" such as museums or art galleries, would epitomize a position:

based on the assumption that the work of art should challenge or disrupt the viewer's expectations about a given image, object, or system of meaning and that the viewer, in turn, requires this disruption to overcome his or her reliance on habitual forms of perception. $(2004,17)$ 
Kester's insights in this regard are just one among many similar contributions. If I have discussed it here, it is because of his interest in examining the use of withdrawal by avant-garde aesthetics, and more specifically, because his concerns are relevant to the Caribbean examples which I will discuss. In the next section I will explore how the aesthetic current criticized here has somehow influenced the main interpretations of the Caribbean histories of artistic modernity.

\section{Caribbean visual culture and objecthood}

As early as 1977, Syed Hussein Alatas had explained how the idea of laziness offered the possibility of blaming the colonized for the dysfunctional elements of colonial rule, which would play a central role in the policing of Asian societies (Alatas 1977). The image of the Caribbean has been subjected to a similar process of emptying and exotification. The construction of the Caribbean as a place of leisure and inactivity has configured a specific visual imaginary (Sheller 2003; Thompson 2006). The centrality of the artwork and its display over the creative process and the multiple agencies involved in that production constitutes, I will argue, one of the main reasons behind the oblivion of practices of artistic withdrawal in the region. The history of Caribbean art has been frequently reduced to a history of temporary large-scale exhibitions and biennials. Being just one manifestation of creative artistic activity among many others, these events have attracted the brunt of critical attention. There is no question that they have played a central role in intraregional consolidation of and in the development of innovative ways of conceiving creativity and spectatorship. However, it is also true that these manifestations have prevailed at the expense of other strategies, restricting our capacity to envisage through curating alternative articulations of artistic agencies and spatial linkages.

In dealing with the origins of the "exhibitionary complex", Tony Bennett presented it as

a history, then, of the formation of a new public and its inscription in new relations of power and knowledge. But a history accompanied by a parallel one aimed at the destruction of earlier traditions of popular exhibition and the publics they implied and produced. $(1996,68)$

Caribbean curatorial history is intersected by this uneven distribution of visibility and display of discourses, subjects and objects. From a very early time, the form of national and regional mega-exhibitions was consolidated in a very specific way. These exhibitions have regulated questions of accessibility, distribution and representation, determining the ways in which different agencies can participate in artistic processes. Exhibitions, Bennett argues (1996, 73), 
2 Although some work has been done in this regard in countries such as Cuba or Jamaica, we still need a more comprehensive view on both how nationalist cultural politics has conditioned curatorial interventions, and on how these interventions have instituted alternative strategies and means. "made the order of things dynamic". Nevertheless, this does not mean that they were any less beholden to national or bourgeois ideological interests, nor that they were freed from colonial and nationalist expectations. Something similar can be said with regard to Caribbean concerns in general, and this would be an interesting path to pursue. ${ }^{2}$

This imaginary overshadows both the centrality of work and labour in the configuration of a Caribbean emancipatory imaginary, and the impact of that imaginary in the configuration of transnational struggles and radical politics. What is remarkable is how this genealogy has permeated the discourses that attempt to challenge that logic from a Caribbean perspective. In many cases, the critical value of an artwork is granted by its ability to respond in ironic and imaginative ways to those exotic expectations. Challenging the main foundations of this imaginary has been a central concern in the agendas of contemporary Caribbean creators. In trying to contest the inheritance of the colonial gaze within the imaginaries of the picturesque (Sheller and John 2004; Thompson 2006), the politics and times of reception of Caribbean visuality (Wainwright 2012), and the commoditization of racial and sexual difference within and beyond the region (Kempadoo 2013; Mohammed 2011; Stephens 2013), a strong emphasis has been placed on exploring and categorizing the counter-narratives elaborated by Caribbean artists. Michelle Stephens, who has extensively analysed the creative practices emerging at the end of the 2000s, identifies an interest in exploring "not just ... what Caribbean art represents - timelessness, insularity, popular urban spaces, myths, cultural crossroads - but rather ... what Caribbean art does" $(2013,17)$.

A similar concern is expressed by the Trinidadian artist Christopher Cozier, who emphasizes the importance of determining how Caribbean discourses are displayed and commodified:

In a place like the Caribbean, we cannot take the agency of portraiture for granted, in the aftermath of a much longer history of topographical and anthropological representations. The subject position - or the role of the subject - within the frame or field of pictorial representation is highly contested. Standard regional historical narratives of the Caribbean recount or register developmental shifts from persons being privately owned property - indentured workers and colonial subjects - to being citizens - of a republic, for example. But in the pictorial domain, we are still anthropological, cultural, national, ethnic or electoral commodities and signifiers. We remain labelled but nameless images. (Cozier 2011, 9)

Cozier's interest in determining the agency of Caribbean art brings certain elements of interests to the fore. His statement attempts to move beyond that idea, highlighting the importance of not only creating counter-discourses, but also elaborating tools actively to control artistic agency. Cozier stresses the importance of controlling the fluxes of art commodification not only by 
3 Unlike Jamaica and Barbados, Trinidad lacks a solid public infrastructure of contemporary art institutions. The development of modernist trends in the country owes much to initiatives such as these. turning external stereotypes around, but also by developing strategies that might encourage active ways of reversing the commodified status of Caribbean art as a tradeable and exportable good. Furthermore, Cozier asks for an alternative understanding of artistic agency, one that refuses to take for granted "a much longer history of topographical and anthropological representations". The Trinidadian artist himself has offered a good example of this by engaging actively in the creation of art platforms such as CCA7 or Alice Yard in Port-of-Spain, which have been decisive in the development of a sphere of discussion and critical engagement with Trinidadian culture since the early $2000 \mathrm{~s}^{3}$

Caribbean art is full of alternatives to this conundrum. Socially engaged art projects, artist-run spaces, pedagogical practices and curated vernacular manifestations (such as carnival) have generated much less attention than biennials or international mega-exhibitions (as exceptions to this point we can mention Tancons [2012]; Thompson [2012]). Despite this fact, they have channelled some of the most innovative and daring artistic initiatives arising from the region. These practices are in many cases fuelling tangible transformations that touch upon organizational and structural conditions of artistic practice across the Caribbean. They aim to configure a space of negotiation where the weight of genealogies and potential insurgent public arenas can be developed with the array of alternative forms of display and coexistence.

In this sense, the dependence in Caribbean criticism on artistic discourses and the exhibition format overshadows the strategies undertaken by Caribbean artists to escape external categorizations and thematizations. Acknowledging the importance of these practices does not imply the creation of a parallel, independent history in which art exhibitions and artistic discourses are disengaged. It means recognizing that Caribbean curatorial practices reflect a porous, tensioned field composed of competing and heterogeneous practices, agencies and motivations, in which biennials and art exhibitions are just two possibilities among many others. Through this lens, a whole set of possibilities would stand against the commodification and exotification of the Caribbean imaginary. I will now explore some specific manifestations related to this understanding, linking them to the main questions posed thus far.

\section{Caribbean curatorial genealogies of withdrawing}

In 1989 a group of artists and curators assembled in Havana to play baseball. In 1992 an anti-biennial was organized that eschewed orthodox exhibition spaces and taking shelter in private, peripheral houses in Santo Domingo. 
In 2009 an artist refusing to exhibit anything went on strike in the context of a group exhibition opening in Martinique. These are just a few examples of acts of withdrawal carried out by Caribbean artists in recent decades. Throughout my case study we find a concern with (in)visibility and spectacle, and also with the exhaustion of the temporary exhibition curatorial format. My examples occupy a vast trajectory of using withdrawal in productive, affirmative terms. They pursue a thorough transformation of the structures surrounding artistic labour in the Caribbean. In so doing, they offer a good point for rethinking the histories of curating in the Caribbean. Contingent upon a similar set of issues and enacting (apparently) similar responses, these practices inform a Caribbean creative genealogy based on the act of fleeing. This, as I will assert, encompasses tactical adjustments, mo(ve)ments of ideas and people, and active reconfigurations of place(s) and space(s), articulating what Michaeline Crichlow and Patricia Northover have defined in other contexts as processes of "fleeing" and "homing" (2009; see also Crichlow 2012).

La plástica cubana se dedica al béisbol (Cuban Art Dedicates Itself to Baseball), the first project I will mention, took place in late September 1989 in the José A. Echevarría stadium in Vedado, Havana. Several Cuban artists, critics and curators, including René Francisco, Antonio Eligio Fernández "Tonel”, Glexis Novoa, Luis Gómez, Gerardo Mosquera and Iván de la Nuez, organized a baseball game as a protest to the situations of censorship that in

4 Mere months prior to the game, René Francisco and Eduardo Ponjuán's exhibition Artista Melodramático was censored, and Marcia Leiseca, then Vice Minister of Culture, was fired. various ways conditioned the Cuban art scene in those years. ${ }^{4}$ The motto for the project was: "Since we cannot make art, we will play baseball". This event was part of a general phenomenon of withdrawal characterizing Cuban artistic practice at the turn of the 1980s, a movement described by Rachel Weiss as

an abandonment of the public - as site, audience, and aspiration; a retreat from an ethic of collectivism; a defensive restoration of the visual in visual art; shifting fortunes for the literal and the metaphoric, shifting of artists' self-positioning relative to official institutions, and shifting of those institutions' own evolutionary logic. (Weiss 2011, 158)

In this case, withdrawal followed an excess of political effervescence that occurred in discursive terms. It implied a change of strategy against the backdrop of the closure of the exhibitionary as a platform of expression. It also arose as a tactical and active occupation of the space of baseball, Cuba's national sport. The choice of baseball was full of connotations. On the one hand, this particular game countered the popular and spectacular nature of baseball in Cuba, making explicit to the revolutionary establishment the situation of atrophy deriving from the difficulties of producing art in contexts of 
5 This process has been well documented. Worthy of mention in this regard are the essential contributions of Luis Camnitzer, Rachel Weiss, Gerardo Mosquera and Lupe Álvarez, among many others. censorship. Furthermore, in the event the deployment of physical energy and the meeting of fellow artists served the main conveyors of aesthetic value.

The 1989 action brought together a local community of artists sharing similar representational burdens. Occurring less than two months prior to the fall of the Berlin wall, Cuban Art Dedicates Itself to Baseball used withdrawal to reinforce a sense of artistic community, thereby productively and contextually repositioning the role of artistic agency and productivity in Cuban society. The consequences were singular: many of the players left the country thereafter, creating an impasse in Cuban art that was only eclipsed after several years, and at the expense of a new shift in creative strategies. The recent history of Cuban art is full of similar acts of withdrawal and insubordination against censorship and institutional control. ${ }^{5}$

During the experimental effervescence of the 1980s, tensions frequently arose between artists and the most reactionary sectors of state cultural bureaucracy. Although the discrepancies increased by the end of the decade, when actions such as Cuban Art Dedicates Itself to Baseball took place, by the beginning of the decade a sociological inquiry into the values and iconography of the revolution was already set in motion. Generally sympathetic about the evolution of Cuban art during the 1980s, Camnitzer $(2003,118)$ has discussed how this movement was a consequence of, and not a reaction against, the modernist character of contemporary Cuban art. He mentions, in this regard, the importance of the educational campaign developed in revolutionary times, and also the positive influence of having an "enlarged public". Withdrawing from the space of the art institution, then, posed a direct challenge to cultural bureaucracy and censorship. Only by exiting certain spaces, the Cuban Art Dedicates Itself to Baseball affirms, could the strategies of control and censorship be overturned. In our project, censorship and self-censorship emerge as a complex reality. With the last years of the 1990s in mind, Camnitzer notes:

Self-censorship in Cuba operates on two levels. One is in regard to the tenor of the actual creative work being produced; the other is what is said in meetings. Both modes do not necessarily happen simultaneously. Until recently, discussions were very open, and nobody seemed overly worried about making theoretical criticism and analysing the situation. There is generally more insecurity about how far the artist can go with the creative work, but ... it is more an issue related to where the pieces will be presented than to what the pieces are communicating. (Camnitzer 2003, 132)

Significantly enough, Camnitzer places emphasis on spatiality rather than on discourse and representation.

The second project I will consider here, Silvano Lora's Bienal Marginal (Marginal Biennial), also originated as a protest against the restriction of 


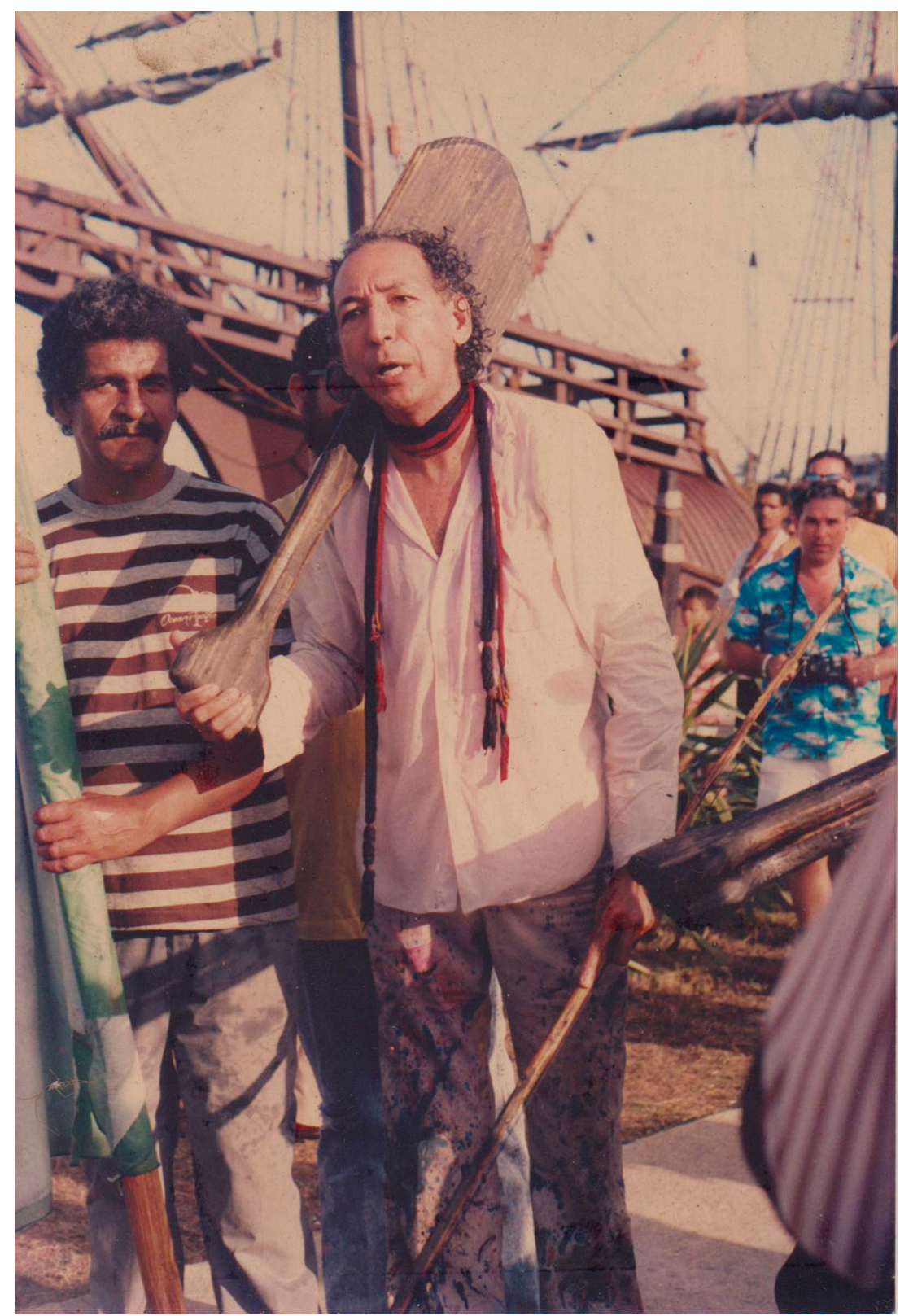

Figure 1. Silvano Lora. 1992.

national, official institutionalism (Figures 1-3). Lora's anti-biennial arose in the Dominican context of cultural and media overexposure linked to the commemoration in 1992 of "Columbus's arrival in the Americas". The Marginal Biennial aimed to exhibit the artworks which were rejected by the Caribbean 


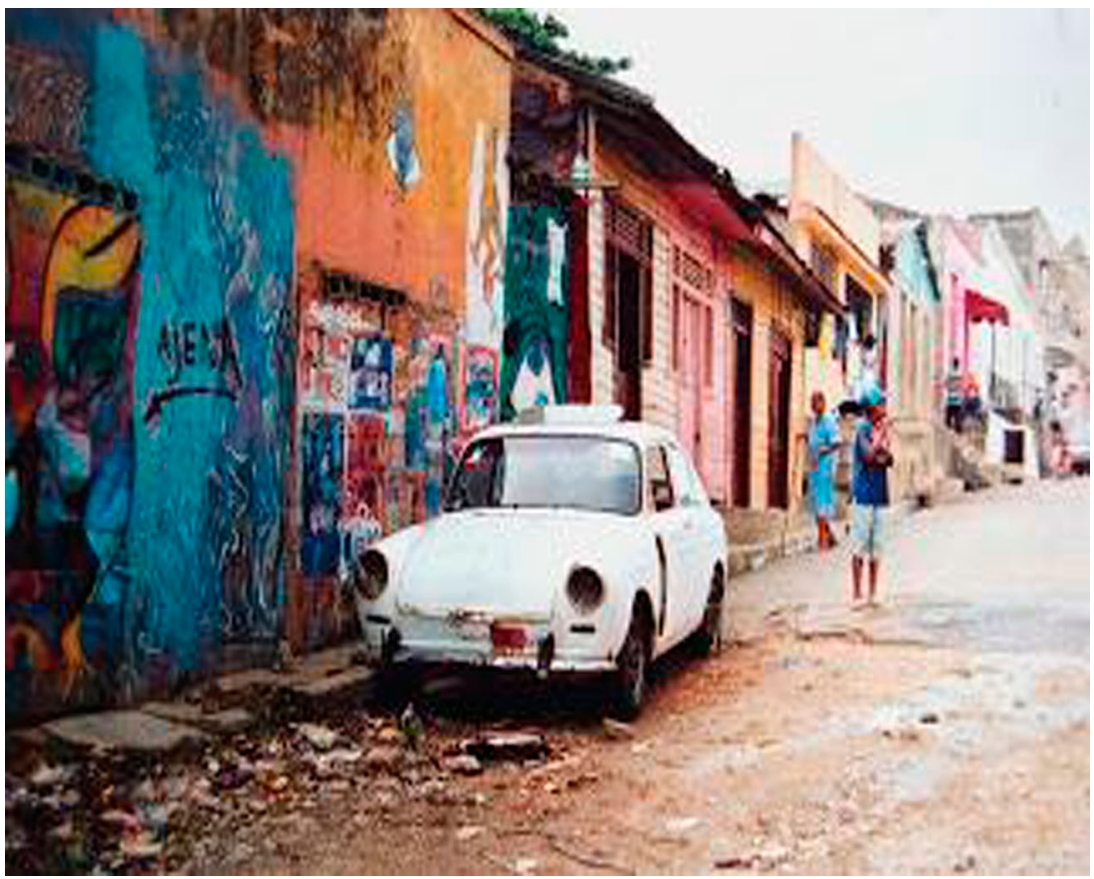

Figure 2. Silvano Lora's Marginal Biennial. Santo Domingo (Dominican Republic). 1992.

Biennial in 1992, including - then - experimental artistic manifestations such as performance and installation art not subsumable within the expressive ethos of national identity.

The Caribbean Biennial was an idea of CARICOM and UNESCO to promote internationally the artistic production of the region. After a long deliberation and several unsuccessful attempts at finding a venue, a proposal was made in 1987 by the former Galería de Arte Moderno de Santo Domingo (presently the Museo de Arte Moderno de Santo Domingo). In 1992 the Dominican Republic launched the project to coincide with the Quinto Centenario del Descubrimiento de América. The biennial was a multitudinous event, with more than three hundred artists from thirty countries in its first edition. Its initial title was "Bienal de Pintura del Caribe y Centroamérica", which illustrates two of its main objectives: the prevalence of "traditional" artistic media, and an expanded notion of the Caribbean, which included continental countries. The biennial sought to serve as a point of convergence for artists from across the region, as a source of artistic innovation, as well as a platform for international recognition and visibility. The Caribbean Biennial thus appeared as the first regional periodical event (the San Juan Poly-Graphic Biennial had a Latin American focus, and the Havana Biennial would opt for a third world, intercontinental perspective). 


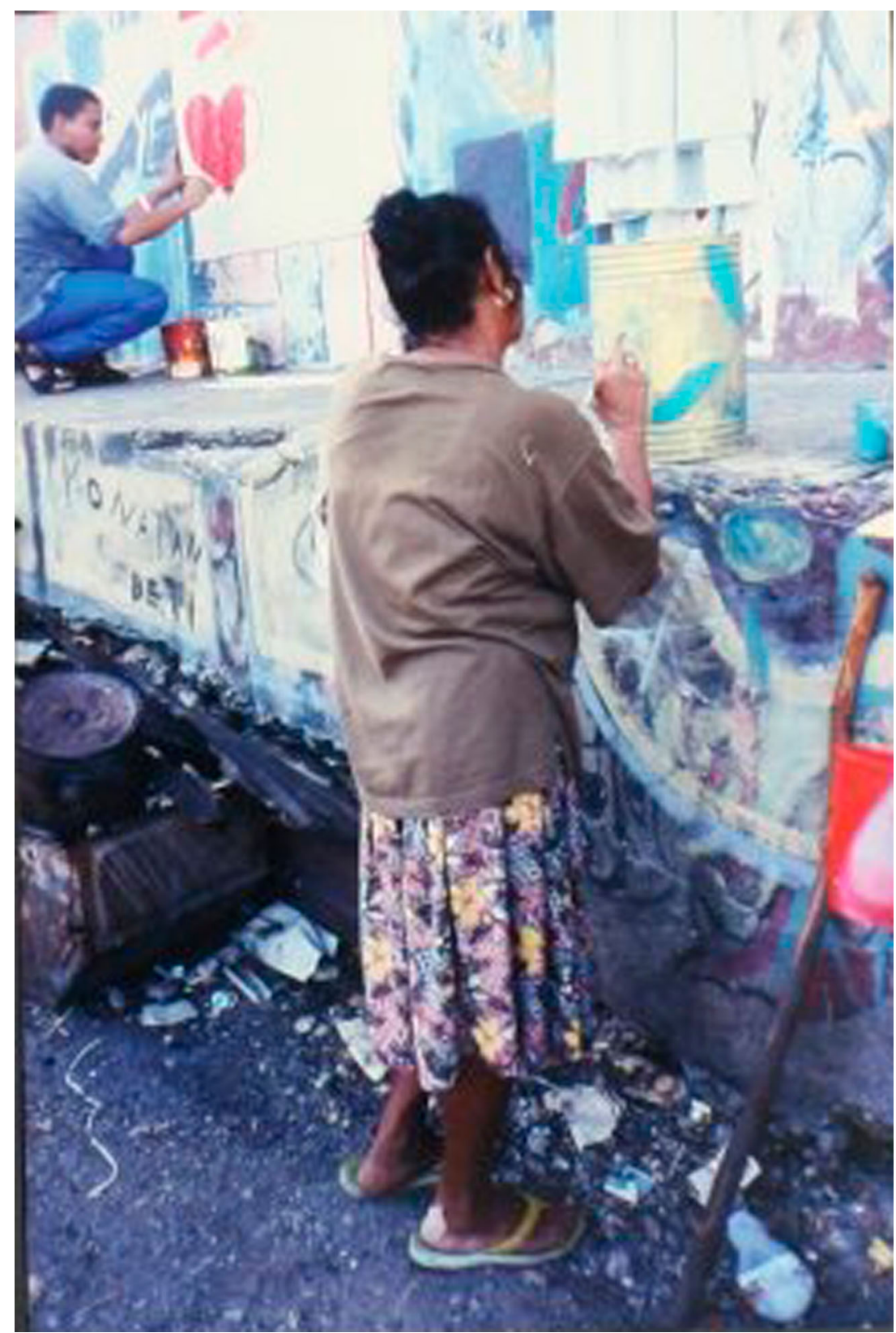

Figure 3. Silvano Lora's Marginal Biennial. Santo Domingo (Dominican Republic). 1992.

The circumstances under which the "original" Caribbean Biennial came into being are particularly interesting for the concerns of this essay. The event originated through interests partially external to the Caribbean. It 
lacked any spatial connotation until it landed in Santo Domingo as part of the cultural paraphernalia of Balaguer's nationalist appropriation of the Columbus Quincentennial (Viala 2014). Although it intended to showcase "what was new" in the region, its originality and aesthetic value were compromised by decisions such as imposing a quota system among countries, creating a prize, and excluding idioms such as installation and performance and video art despite their decisive role in the artistic processes of renewal taking place at the beginning of the 1990s. More importantly, the project soon confronted financial problems. In 1996, after three editions had been celebrated, the event closed its "doors". After an attempt at resuscitating the project in the format of the 2010 Triennial (this time open to any artistic manifestation), no further editions of the event have taken place to this date. The Caribbean Biennial, therefore, is part of the history of a precarious official art system and to some extent of the perpetuation of colonial logics and expectations within postcolonial regional and nationalist cultural agendas.

Lora's anti-biennial was not simply a Dominican Salon des Refusés reacting against that model; the project also withdrew from the space of official institutions and moved the event to peripheral locations in Santo Domingo, denouncing the cultural spectacularization and segregation behind the official commemorative programme envisioned by President Joaquín Balaguer. In this case, the act of withdrawal implied a broader community than in the Cuban example, since spaces of "national culture" were abandoned so as to insert art within an expanded public arena. Artistic labour was also framed here differently: creative agency was not abandoned; it was just oriented toward durable, non-marketable, community-based strategies. The Caribbean Biennial was conceived as a representational event (in the sense of both establishing a clear difference between viewers and artists, and of "covering" the entire Caribbean region) oriented toward heterogeneous audiences. It was based on national representations and a system of prizes. Contrary to this logic, Silvano Lora's anti-biennial framed artistic production as a collective endeavour. The event included the execution of murals designed and produced by sectors of local communities and the organization of workshops open to all kinds of audiences.

The Marginal Biennial was conceived as a "third world event". It was based on the belief that the issues affecting the Dominican artistic context were

6 Both the Caribbean Biennial and the Marginal AntiBiennial were part of the few events including the continental Caribbean. However, even if the latter was driven by a political shared throughout the Caribbean region and the Americas. ${ }^{6}$ In Lora's initiative, the presence of artists from countries throughout the hemisphere triggered a sense of contagious and expansive dynamics that was sought to create an alternative geo-cultural mapping. The Marginal Biennial was thus driven by the sense of "self-conscious, critical regionalism" associated with the "South history of biennials" (Gardner and Green 2013, 444). At a time when Caribbean art was gaining international attention and being externally commoditized, the anti-biennial reacted against the lack of contextual rooting 
enactment of national "Hispanism" in cultural politics, this inclusion implied something totally different in the Marginal Biennial, where it stood for an articulation with third-worldist emancipative agendas and continental unity. of many events of that period, engaging location actively both on a local and a transnational level.

Joëlle Ferly's L'Art de faire grève, the last example I will consider, also tackles the issues of cultural institutionalism, artistic labour and location. When invited to the opening of the collective exhibition Entre-Vues, held at the Fondation Clément in Martinique, the artist decided to go on strike and meandered around the opening-night event greeting people. The action was planned within the framework of a very specific context: the Fondation, the main art centre in the Francophone Caribbean, is built on the grounds and the economy of a sugar plantation, while also being managed by the descendants of one of the wealthiest families in France. Far from Fort-de-France, the audience of the Fondation is composed of a minority of bekés, the white population directly descended from colonists. Therefore, whenever the work of Guadelouupean and Martinican artists is displayed there, it becomes inserted within a lopsided economy of vision. Although these artists may be providing artistic discourses on Caribbean issues, they generally have no agency as to how those discourses are displayed, commoditized, collected and inserted within larger narratives. Ironically enough, Entre-Vues was an exhibition about the gaze in Caribbean photography. Ferly's grève was not, however, directed only against exhibitions; it was also about the politics of spectatorship and the institutional dynamics in which these exhibitions are embedded. Spaces such as the Fondation Clément have been essential in promoting contemporary artistic production in the Francophone Antilles. This, however, has been at the expense of a reconsideration of the role of local populations in the cultural milieu. The economic divide between a small elite in control of most businesses and a larger population with French citizenship but which is highly precarious is maintained and ever-present in cultural activities such as art (Figures 4-6).

It is worth noting that what lies at the core of actions such as L'Art de faire grève is a resistance against being categorized and displayed as a Caribbean artist. In her work during the same years, the artist dealt with personal experiences of rejection in that sense. Please Pass the Dark Chocolate Over Before I Commit Suicide (2006-2007) consists of a single video monitor and an interactive workshop. The video shows a series of concise black lines bordering a white square. These lines end up forming a black box that after a while we begin to associate with the ones included in Equal Opportunity Monitoring Forms. As we hear the sound of Ferly "marking" the different boxes, some sentences and words, although always incomplete, appear along with the common motto: "Please specify"; "Write my ethnic origin as: '[ot]her white background', 'black British', 'Irish', 'Chinese'," and so on. After the speed is slowed, the images revert to Malevich- and Mondrian-like forms, and then the projection stops. For the presentation of this project, Ferly provided a table where the public could sit and fill out the original forms. This first took place in France, where Equal Opportunity Forms are not common. In projects 


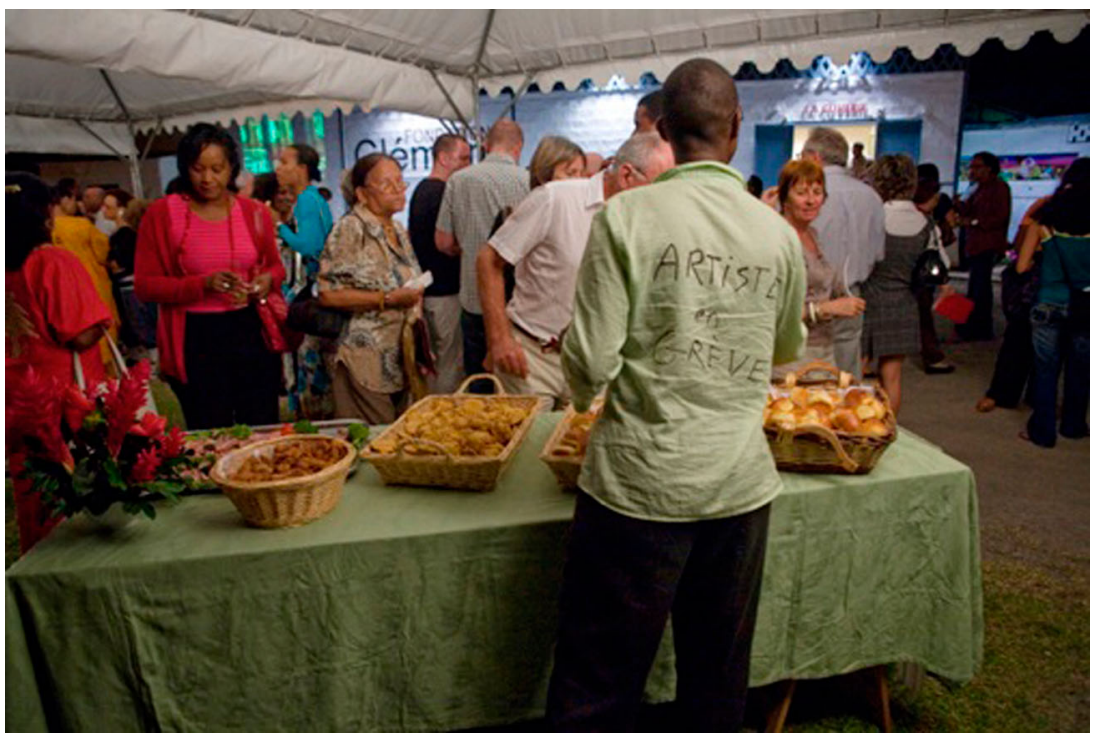

Figure 4. Joëlle Ferly. L’Art de Faire Grève. Fondation Clément (Martinique). 2009.

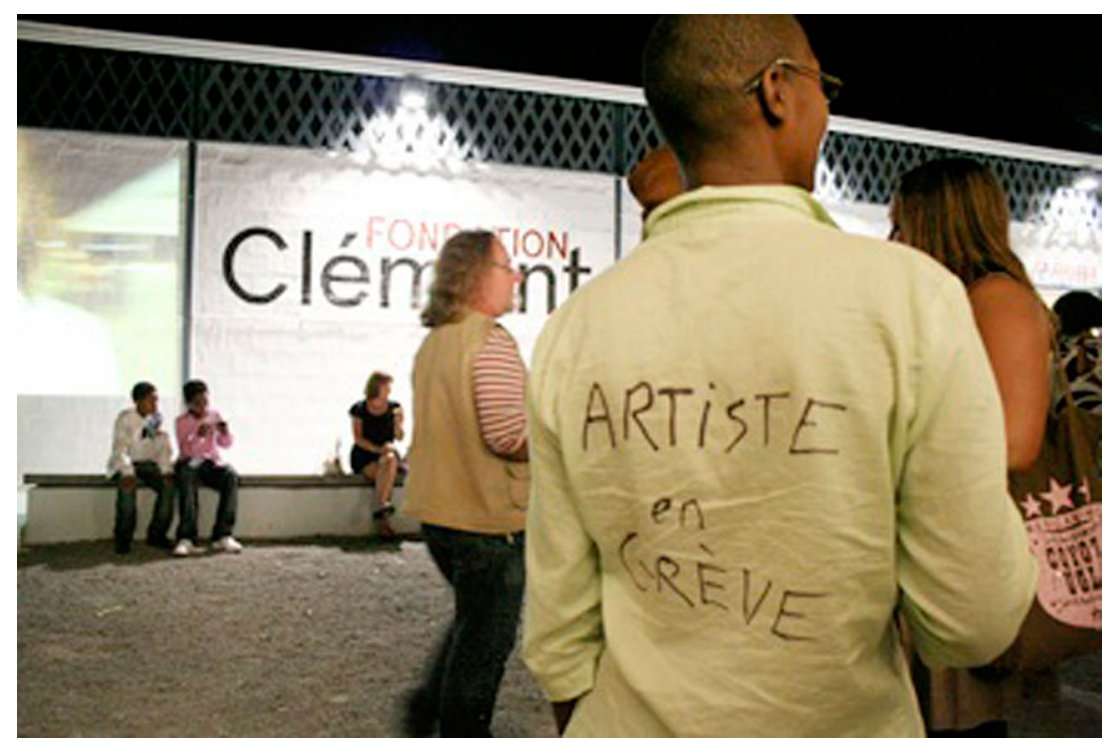

Figure 5. Joëlle Ferly. L’Art de Faire Grève. Fondation Clément (Martinique). 2009.

such as this one, Ferly situates her work within a context where it is impossible to "escape from the box". By focusing on the political economy of difference,

7 Ferly remembers the case of a Swedish artist living in and not on one single categorization, ${ }^{7}$ Ferly reflects upon the complexity of negotiating her position as an artist. 
London whose English was perfect, save for a slight accent. This speaks of the versatility of the project.

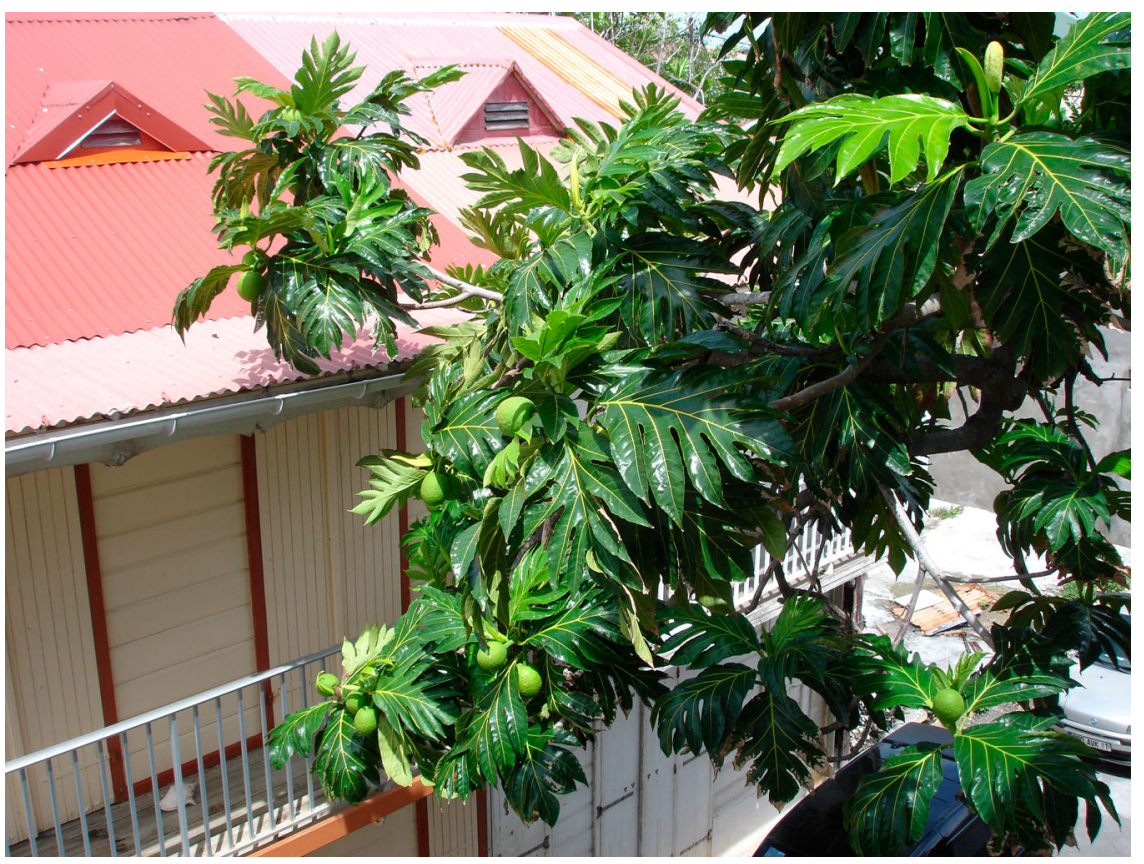

Figure 6. L'Artocarpe. Le Moule (Guadeloupe).

It is my contention, however, that L'Art de faire la grève constitutes a step forward from previous projects such as Please Pass the Dark Chocolate Over. Despite the sense of humour and the idea of projecting the nonsensical reasoning of administrative bureaucracies, in this case the performance is directed toward a perfectly defined target: the most important exhibition venue in the Francophone Caribbean. Conscious of the pressing need to make a statement, Ferly's L'Art de faire la grève responds to a very specific series of circumstances. In 2009 the Francophone Caribbean was the scene of various protests against social inequality and economic precariousness. Ferly's act of defiance took place after the creation of the LKP (Liyannaj kont pwofitasyon) collective during the same year (see Bonilla 2015). Ferly sought to translate LKP's plea for sovereignty and struggle against metropolitan, "foreign" interference (which led to a 44-day strike between January and March of 2009) in the Francophone Caribbean cultural milieu. These events were part of the largest protest movement to take place in the Francophone Antilles since they became Departments d'Outre Mer (DOM).

After completing her artistic training in Paris and London, Ferly settled back in Guadeloupe in 2008, where she became involved in the political situation of the islands. L'Art de faire grève intended to bring to the space of the art institution the situation of crisis affecting the DOMs. In the project statement, Ferly makes reference not only to the 2009 strikes, but also to how 
8 For instance, L'Artocarpe has created bonds with other similar artistmanaged spaces and curatorial initiatives in Trinidad, South Africa and Senegal. they were emptied of meaning by the media operating in "France hexagonale". She is concerned with how the activist potential of local movements is compromised by the opportunistic tendencies of local and metropolitan public opinion, including the French Left. Similarly, L'Art de faire la grève questions the extent to which discursive agency can be withdrawn when that agency is controlled and displayed "chez le beké". Her position toward the Fondation is, nevertheless, ambivalent, since she recognizes that the institution has been crucial in originating and disseminating Antillean contemporary practices.

Perhaps the weakest point of L'Art de faire la grève is its incapacity to envisage any alternative community or audience for artistic practice. There is no response to the questions posed by the action beyond the negativity of refusing institutional control and the grammar of exhibition practice. A response would subsequently be provided, in the form of L'Artocarpe, the first artist-managed space in Guadeloupe. Founded by Ferly, L'Artocarpe is a federation of local artists who use the space for developing their work and for exchanging impressions. L'Artocarpe is also an art residency that encourages international visitors to interact with local creators through many activities, such as open conversations, workshops and studio visits. The visitors are therefore not committed to transform their stay in a perfectly finished product, such as an exhibition. On the contrary, they are intended to use the space and the structure of L'Artocarpe to advance with work in progress and to conduct practical research. Such initiatives have connected the community of Guadeloupean artists with areas outside France, loosening the dependence toward the metropolitan space and its respective art scene. ${ }^{8}$ In this sense, by positioning itself at the margins of process-oriented, long-term creativity, the residency enables ongoing feedback and international exchange despite the cultural oblivion motivated by the organizational distribution of the Caribbean DOMs. L'Artocarpe can thus be seen as an attempt to complement the negativity and irony of Ferly's individual performances, serving as a platform where space is actively and continuously restaged and reframed. Here, withdrawing is transformed into infrastructural production, and collective and individual agencies are interlaced in open, insurgent ways.

The examples I have discussed function by undoing and then deepening the spatial - temporal shattering of temporary exhibition practices, which, as I have asserted, have significantly shaped the histories of Caribbean artistic production. In these projects, withdrawal is used as a form of critical positioning. 
It works as a way of compromising institutional and infrastructural dynamics and platforms perceived as negative or narrow minded. The Cuban case is a bit different because the baseball action implied the subsequent "real" withdrawal from the country of many of the participants. In any event, the projects examined here emerge as a response to the stagnation of local art systems and to the lack of infrastructural agency of artistic communities. In all the cases, "conventional" forms of production are abandoned, and this very abandonment becomes the conveyor of aesthetic value and meaning in each action. In the four examples discussed here, community and collective agency are not prefigured, but actively produced. All of them arise from an interest in inserting artistic practice within a critical conceptualization of space and location, one that correlates acts of "fleeing" and "homing". These projects can be seen as establishing linkages to a chain of departures transcending national borders and specific agendas and establishing what Mezzadra (2012, 17-20) has called "movements of secession".

My examples can be divided into two categories: Cuban Art Dedicates Itself to Baseball and L'Art de faire la grève offer antagonist responses to censorship, institutional pressure, economic privilege and cultural segregation. On the other hand, the Marginal Biennial and L'Artocarpe share this dimension, yet they also produce affirmative, instituent actions. At the same time, these two projects created a resonance extending beyond the local predicaments for which they sought a response. The Marginal Biennial was not merely a response to the "official" Santo Domingo of 1992, or a negative version of the Caribbean Biennial. It also entailed an organic consideration of the Caribbean region linked to other spaces of political and cultural emergence. Similarly, the negativity of Joëlle Ferly's performance was transformed into a positive measure through the creation of L'Artocarpe. Both projects conceive collaborative art as a durable and productive intervention, going beyond a simple transformation of spectatorship within the context of art exhibitions (Bishop 2012; Wright 2004).

The questions raised through the use of withdrawal offer a good vantage point from which to grasp the main concerns that have centred Caribbean artistic practice over the last two decades. The projects outlined here integrate alternative, insurgent creative genealogies, while also evidencing how Caribbean creativity is compelled to face a broad redefinition of cultural dynamics in contexts of institutional precariousness and contested public spheres. At the same time, they also straightforwardly problematize the function of art in relation to the local social fabric, while questioning issues of accessibility, privilege and individual and collective agency. More than standing for "good or bad responses", then, they evidence a fruitful movement, especially in terms of how debates on cultural and institutional practices should be framed. 


\section{Acknowledgements}

This work was supported by a Post-Doctorate Fellowship granted by the Portuguese Fundação para a Ciência e Tecnologia (FCT). It was also supported by the research project 'El artista y el dolor: El sufrimiento como limite de la representación en la cultura artística contemporánea (HAR2012- 31321)'. The developed research was produced over several long-term research stays in the Caribbean and the United States (Lilly Library, Duke University, 2013; NYU Bobst Library, New York University, 2015). Finally, the text benefitted from the conversations with Denisa Tomkova and Fernanda Gil Costa.

\section{References}

Alatas, Syed Hussein. 1977. The Myth of the Lazy Native: A Study of the Image of the Malays, Filipinos and Javanese from the 16th to the 20th Century and Its Function in the Ideology of Colonial Capitalism. London: Frank Cass.

Bennett, Tony. 1996. "The Exhibitionary Complex." In Thinking about Exhibitions, edited by Reesa Greenberg, Bruce W. Ferguson, and Sandy Nairne, 58-81. New York: Routledge.

Bishop, Claire. 2012. Artificial Hells: Participatory Art and the Politics of Spectatorship. London: Verso.

Bonilla, Yarimar. 2015. Non-Sovereign Futures: French Caribbean Politics in the Wake of Disenchantment. Chicago: University of Chicago Press.

Buck-Morss, Susan. 2009. Hegel, Haiti and Universal History. Pittsburgh: University of Pittsburgh Press.

Camnitzer, Luis. 2003. New Art of Cuba. Austin: University of Texas Press.

Cozier, Christopher. 2011. "Notes on Wrestling with the Image." In Wrestling with the Image: Caribbean Interventions, edited by Christopher Cozier and Tatiana Flores, 6-15. Washington, DC: World Bank.

Crichlow, Michaeline A. 2012. "Making Waves: (Dis)Placements, Entanglements, Movements." The Global South 6 (1): 114-137.

Crichlow, Michaeline A., and Patricia Northover. 2009. Globalization and the Post-Creole Imagination. Notes on Fleeing the Plantation. Durham, NC: Duke University Press.

Fischer, Sybille. 2004. Modernity Disavowed: Haiti and the Cultures of Slavery in the Age of Revolution. Durham, NC: Duke University Press.

Gardner, Anthony, and Charles Green. 2013. "Biennials of the South on the Edges of the Global." Third Text 27 (4): 442-455.

Kempadoo, Roshini. 2013. "Gazing Outward and Looking Back: Configuring Caribbean Visual
Culture." Small Axe: A Caribbean Journal of Criticism 17 (2 41): 136-153. doi:10.1215/079905372323364.

Kester, Grant. 2004. Conversation Pieces: Community and Communication in Modern Art. Berkeley: University of California Press.

Kester, Grant. 2011. The One and the Many: Contemporary Collaborative Art in a Global Context. Durham, NC: Duke University Press.

Kester, Grant. 2013. "The Device Laid Bare: On Some Limitations in Current Art Criticism." E-Flux 50. http://www.e-flux.com/journal/50/59990/the-devicelaid-bare-on-some-limitations-in-current-art-criticism/ Mezzadra, S. 2012. Direito de fuga. Lisbon: Unipop.

Mohammed, Patricia. 2011. Imaging the Caribbean: Culture and Visual Translation. New York: Palgrave Macmillan.

Sheller, Mimi. 2003. Consuming the Caribbean: From Arawaks to Zombies. London: Routledge.

Sheller, Mimi, and Urry John, eds. 2004. Mobilities: Places to Play, Places in Play. London: Routledge.

Stephens, Michelle. 2013. "What Is an Island? Caribbean Studies and the Contemporary Visual Artist." Small Axe: A Caribbean Journal of Criticism 17 (2 41): 8-26. doi:10.1215/07990537-2323292.

Tancons, Claire. 2012. “Curating Carnival?” In Curating in the Caribbean, edited by David Bailey, Alissandra Cummins, Alex Lapp, and Allison Thompson, 58-81. Berlin: Green Box.

Taylor, Christopher. 2014. "The Refusal of Work: From the Postemancipation Caribbean to PostFordist Empire." Small Axe: A Caribbean Journal of Criticism 18 (2): 1-17. doi:10.1215/079905372739812.

Thompson, Krista. 2006. An Eye for the Tropics: Tourism, Photography, and Framing the Picturesque. Durham, NC: Duke University Press. 
Thompson, Krista. 2012. "How to Install Art as a Caribbeanist." In Curating in the Caribbean, edited by David Bailey, Alissandra Cummins, Alex Lapp, and Allison Thompson, 97-113. Berlin: Green Box.

Viala, Fabianne. 2014. The Post-Columbus Syndrome: Identities, Cultural Nationalism, and Commemorations in the Caribbean. New York: Palgrave.
Wainwright, L. 2012. Timed Out: Art and the Transnational Caribbean. Manchester: Manchester University Press.

Weiss, Rachel. 2011. To and from Utopia in the New Cuban Art. Minneapolis: University of Minnesota Press.

Wright, S. 2004. "The Delicate Essence of Artistic Collaboration." Third Text 18 (6): 533-545. doi:10. 1080/0952882042000284943. 